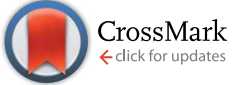

Cite this: Chem. Sci., 2015, 6, 4599

\section{Bidirectional photoswitching of magnetic properties at room temperature: ligand-driven light-induced valence tautomerism $\uparrow$}

\begin{abstract}
Alexander Witt, Frank W. Heinemann and Marat M. Khusniyarov*
Valence tautomeric (VT) metal complexes are highly promising bistable molecular compounds for applications as molecular switches in molecular electronics and spintronics. Although VT species can be switched with light, the photoswitching in all reported systems requires very low temperatures (usually below $20 \mathrm{~K}$ ) because photoinduced states are highly unstable at room temperature. The thermal instability hinders any practical application of these complexes in genuine devices. In this report, for the first time we demonstrate photoswitching of VT species and associated magnetic properties at room temperature. The bidirectional photoswitching in solution is due to cis-trans photoisomerizable 4-styrylpyridine ligands deliberately integrated into cobalt dioxolene molecular complexes. The novel type of photoswitching has been coined Ligand-Driven Light-Induced Valence Tautomerism (LD-LIVT). The photoconversion of VT states of $28 \%$ has been achieved in solution at room temperature. The photoinduced states show extraordinary thermal stability for hours at room temperature, as compared to common nanoseconds reported previously. The switching proceeds at molecular level with the effective photoswitching rate of $3 \times 10^{13}$ molecules per s under our conditions. Consequently, this work may open new horizons in applications of molecular switches based on VT metal complexes in molecular devices functioning at room temperature.
\end{abstract}

Received 13th January 2015 Accepted 22nd May 2015

DOI: $10.1039 / \mathrm{c} 5 \mathrm{sc} 00130 \mathrm{~g}$

www.rsc.org/chemicalscience

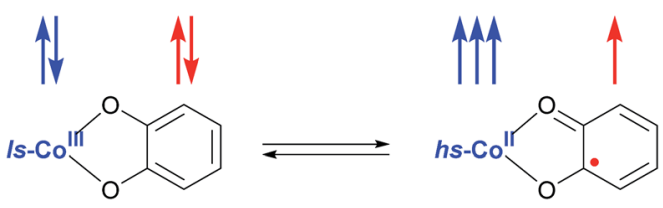

intramolecular electron transfer to occur, which gives rise to distinctly different electronic states (redox isomers). Particularly interesting are VT cobalt dioxolenes because intramolecular electron transfer is accompanied by a spin state change at the cobalt center resulting in reversible switching between diamagnetic low-spin (ls) cobalt(III) $(S=0)$ and paramagnetic high-spin (hs) cobalt(II) $(S=3 / 2)$ ions. Greatly differing magnetic properties of the two states and the opportunity to switch reversibly between them by external stimuli render VT cobalt complexes highly attractive for applications as molecular switches, sensors and molecule-based memory units. ${ }^{3-6}$

The switching in VT metal complexes can be triggered by temperature, pressure, magnetic field, soft X-rays or by light. ${ }^{7}$

Friedrich-Alexander-University of Erlangen-Nuremberg, Department of Chemistry and Pharmacy, Egerlandstr. 1, 91058 Erlangen, Germany.E-mail: marat.khusniyarov@ fau.de; Fax: +49 9131 8527367; Tel: +49 91318527464

$\dagger$ Electronic supplementary information (ESI) available: Derivation of the non-linear regression fitting functions, crystallographic details, magnetization and electrochemical data, EPR and electronic absorption spectra. CCDC 1015850-1015852 and 1058866. For ESI and crystallographic data in CIF or other electronic format see DOI: 10.1039/c5sc00130g
Most of the research in the field is dedicated to the development of thermally switchable VT species. However, switching with light is much more attractive for prospective applications due to high speed of addressing, superior resolution, and high selectivity. It is known that photoswitching in VT metal complexes can be achieved by irradiation into appropriate charge transfer (CT) absorption bands. ${ }^{8}$ However, the lifetime of such photoinduced metastable states is in the order of nanoseconds at room temperature (RT). The metastable states can be stabilized by cooling which allows the photoswitching to be performed only at very low temperatures, usually below $20 \mathrm{K.} .^{9-12}$ Shultz et al. were able to stabilize photoinduced states at higher temperatures up to $90 \mathrm{~K}$ using crystal lattice effects. ${ }^{13,14}$ However, the photoswitching becomes impossible at molecular level in such a case. Thus, all previously reported VT photoswitches operate only at very low temperatures, which results in serious limitations for their use in molecular devices. 
Nonetheless, a photoinduced state might be stabilized by introducing photoisomerizable ligands into VT systems ${ }^{\mathbf{1 5}}$ in such a way that a ligand-based photoreaction affects the energy of redox-active orbitals and thus triggers intramolecular electron transfer. The stability of such photoinduced state is dictated by the stability of the photoisomer of the ligand which can exceed years at RT. ${ }^{16}$ The very first step in this direction has been attempted recently by Frank et al. ${ }^{17}$ Although their spirooxazine-derived ligand maintained photoactivity within a VT cobalt complex, no solid evidence for the photoswitching of VT states at RT has been provided. Thus, VT metal complexes that can be switched with light at RT remained unknown to date.

Our group works on stabilization of photoinduced states in VT and spin-crossover metal complexes by integration of photoisomerizable ligands into bistable species. ${ }^{\mathbf{1 8 - 2 0}}$ Very recently, we have developed a VT cobalt dioxolene system featuring two photoactive trans-4-phenylazopyridine ligands and introduced a new concept for switching VT states called "CoordinationInduced Valence Tautomerism” (CIVT). ${ }^{20}$ Unfortunately, low thermal stability of photogenerated cis-4-phenylazopyridine precluded a detailed examination of photoswitching in this system. To improve photophysical properties of the system we decided to substitute 4-phenylazopyridine with 4-styrylpyridine (4-stypy) ligands that show high thermal stability of both cisand trans-isomers. ${ }^{21}$

Here, we report two VT cobalt complexes trans-6 and cis-6 containing photoactive trans-4-stypy and cis-4-stypy ligands, respectively (Scheme 1). Their molecular and electronic structures are thoroughly investigated by variable-temperature X-ray crystallography, magnetic susceptibility measurements, NMR, EPR and electronic absorption spectroscopy, electrochemistry and titration experiments. For the first time, the electronic states of VT metal complexes are switched with light at room temperature. Consequently, the switching of VT states allows to

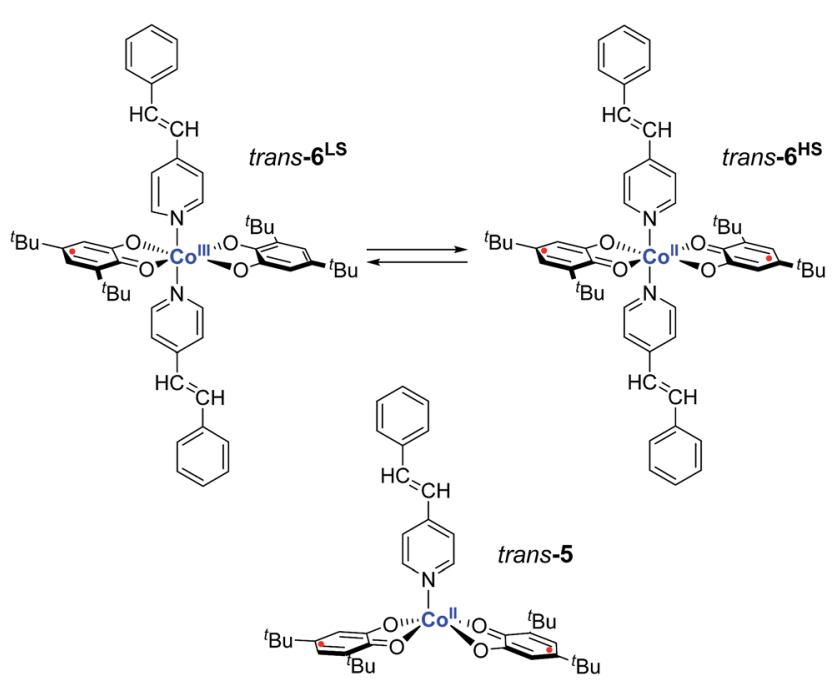

Scheme 1 Cobalt dioxolene complexes trans-5 and trans- 6 with their respective electronic structures: [ls-Co'l'(Cat)(SQ)(trans-4-stypy) ${ }_{2}$ ] (trans$6^{\mathrm{LS}}$ ), [hs-Co"(SQ) ${ }_{2}(\text { trans-4-stypy) })_{2}$ (trans- $6^{\mathrm{HS}}$ ), and [hs-Co" $(\mathrm{SQ})_{2}($ trans4-stypy)] (trans-5). Molecular and electronic structures of cis-5 and cis- 6 are similar except of trans-4-stypy substituted by cis-4-stypy. control magnetic properties with light at ambient temperatures. This opens new horizons for application of molecular switches based on VT metal complexes in functioning molecular devices.

\section{Experimental section}

\section{Materials}

All starting materials and solvents were used as received without further purification unless otherwise noted. Pure anhydrous solvents, required for work under inert atmosphere, were collected from a solid state solvent purification system (Glass Contour System, Irvine, CA) and stored over activated molecular sieves.

\section{Syntheses}

Precursor cobalt tetramer was obtained as a benzene solvate $\left[\mathrm{Co}(\text { tbdiox })_{2}\right]_{4} \cdot\left(\mathrm{C}_{6} \mathrm{H}_{6}\right)_{2.75}$ by a synthetic procedure described by Pierpont et al. ${ }^{22}$ trans-4-Styrylpyridine (trans-4-stypy) was prepared according to a method described by Chiang and Hartung. ${ }^{23}$ cis-4-Styrylpyridine (cis-4-stypy) was obtained in a Wittig reaction as reported by Williams et al. ${ }^{21}$

[Co(tbdiox $\left.)_{2}(\text { trans-4-stypy })_{2}\right]$ (trans-6) was prepared according to a common procedure for bis(o-dioxolene) cobalt complexes: ${ }^{1}$ under inert atmosphere, trans-4-styrylpyridine $(200 \mathrm{mg}$, $1.10 \mathrm{mmol})$ dissolved in toluene $(10 \mathrm{~mL})$ was added dropwise to $\left[\mathrm{Co}(\text { tbdiox })_{2}\right]_{4} \cdot\left(\mathrm{C}_{6} \mathrm{H}_{6}\right)_{2.75}(300 \mathrm{mg}, 0.14 \mathrm{mmol})$ dissolved in hot toluene $\left(50 \mathrm{~mL}, 80{ }^{\circ} \mathrm{C}\right)$. The reaction mixture was stirred overnight at $80^{\circ} \mathrm{C}$ and then stored at $-35^{\circ} \mathrm{C}$ for 3 days before a greygreen precipitate was collected and dried in vacuo $(274 \mathrm{mg}$, yield: $58 \%$ ). Elemental analysis calcd (\%) for $\mathrm{C}_{54} \mathrm{H}_{62} \mathrm{CoN}_{2} \mathrm{O}_{4}$ : C 75.24, H 7.25, N 3.25; found: C 74.99, H 7.24, N 3.32.

[Co(tbdiox $\left.)_{2}(\text { cis-4-stypy })_{2}\right]$ (cis-6) was obtained following a similar synthetic protocol: under inert atmosphere, cis-4-styrylpyridine $(295 \mathrm{mg}, 1.63 \mathrm{mmol})$ was added to a hot toluene solution $\left(70 \mathrm{~mL}, 80{ }^{\circ} \mathrm{C}\right)$ of $\left[\mathrm{Co}(\text { tbdiox })_{2}\right]_{4} \cdot\left(\mathrm{C}_{6} \mathrm{H}_{6}\right)_{2.75}(448 \mathrm{mg}$, $0.20 \mathrm{mmol}$ ). The reaction mixture was stirred for 2 days at $80^{\circ} \mathrm{C}$ and then stored at $-35{ }^{\circ} \mathrm{C}$ for several days before a black crystalline precipitate was collected and dried in vacuo $(503 \mathrm{mg}$, yield: $73 \%$ ). Elemental analysis calcd (\%) for $\mathrm{C}_{54} \mathrm{H}_{62} \mathrm{CoN}_{2} \mathrm{O}_{4}$ : C 75.24, H 7.25, N 3.25; found: C 75.83, H 7.13, N 3.36.

\section{Instrumentation and physical measurements}

Elemental analyses were carried out with a EURO EA analyser from Euro Vector. Magnetic susceptibility data on solid samples were collected using a Quantum Design MPMS-XL SQUID magnetometer. The data were obtained for microcrystalline samples restrained within a polycarbonate gel capsule. DC susceptibility data were collected in the temperature range $2-400 \mathrm{~K}$ at applied magnetic field of $1 \mathrm{~T}$. The program JulX was used for the simulation and analysis of magnetic data. ${ }^{24}$ Electrochemical measurements were performed under nitrogen atmosphere at RT using a standard three-electrode setup with glassy carbon working electrode and platinum rods as counter and reference electrodes. The potentiostat was a $\mu$ Autolab TypeIII. Analyte solutions were prepared in $\mathrm{CH}_{2} \mathrm{Cl}_{2}$ containing $0.1 \mathrm{M}$ ${ }^{n} \mathrm{Bu}_{4} \mathrm{NPF}_{6}$ as supporting electrolyte. All potentials are referenced 
to the $\mathrm{Fc}^{+/ 0}$ redox couple measured after adding ferrocene to the analyte solution. EPR spectra were recorded on a Jeol CW spectrometer JES-FA200 equipped with an X-band Gunn diode oscillator bridge and a cylindrical mode cavity. Simulations were performed using the program W95EPR written by $\mathrm{F}$. Neese. ${ }^{25}$ Irradiation experiments were conducted in situ through a quartz window in the cavity. NMR spectra of trans-6 in solution were recorded in rotating $5 \mathrm{~mm}$ o.d. tubes with Jeol JNM-LA 400 FT NMR spectrometer and processed with Delta V4.0 software provided by Jeol Ltd. NMR spectra of cis-6 in solution were obtained without rotating, in $5 \mathrm{~mm}$ o.d. tubes on a Bruker Avance DRX 400 WB spectrometer and processed with TopSpin 1.3 software. Magnetic susceptibility in solutions were determined by the Evans NMR method. ${ }^{26}$ During the variable temperature and titration experiments the outer tube (standard $5 \mathrm{~mm}$ o.d. NMR tube with a PTFE spindle valve) contained a reference solvent mixture $\mathrm{C}_{7} \mathrm{H}_{8} / \mathrm{C}_{7} \mathrm{D}_{8} / \mathrm{TMS}$ (10/2/1), while the inner tube (capillary tube with $1.5 \mathrm{~mm}$ diameter sealed with inert wax) contained the paramagnetic complex in the same solvent mixture. The irradiation experiments were performed using a rotating $5 \mathrm{~mm}$ o.d. quartz NMR tube with a PTFE spindle valve with the complex solution in the outer tube and the reference solvent mixture in the inner capillary tube. Electronic absorption spectra were recorded with a Shimadzu UV 3600 spectrophotometer. The samples were prepared under anaerobic conditions and sealed in QS Quartz Suprasil cells (10 mm light path) with PTFE spindle valves. Variable-temperature spectra were recorded with an Analytik Jena SPECORD S600 spectrophotometer. The samples were prepared under anaerobic conditions and measurements were conducted inside a glove box using QS Quartz Suprasil cells (10 mm light path). The solutions were continuously stirred with a magnet bar and the temperature inside the cells was monitored. An LOT-Oriel $\mathrm{Xe}(\mathrm{OF})$ arc lamp (1 kW) equipped with an Omni- $\lambda 300$ monochromator was used as a wavelength-variable light source in all irradiation experiments except the in situ irradiation followed by EPR spectroscopy. For the latter, an LOT-Oriel Xe(OF) arc lamp $(150 \mathrm{~W})$ equipped with an Andover bandpass filter (CWL: $322.9 \mathrm{~nm}, T_{\text {max }}: 28.0 \%$, FWHM: $10.6 \mathrm{~nm}$ ) were employed.

\section{X-ray crystallographic data collection and structure refinement}

Suitable crystals were embedded in protective perfluoropolyalkyl ether oil and transferred to the cold nitrogen gas stream of the diffractometer. Intensity data for trans-6 were collected at 120, 295 and $305 \mathrm{~K}$, and for cis-6 at $100 \mathrm{~K}$ on a Bruker Kappa Smart APEX2 (Mo $K_{\alpha}$ radiation, $\lambda=0.71073 \AA$, graphite monochromator). Data were corrected for Lorentz and polarization effects; semi empirical absorption corrections were applied on the basis of multiple scans using $S A D A B S{ }^{27}$ The structures were solved by direct methods and refined by fullmatrix least squares procedures on $F^{2}$ using SHELXTL NT 6.12. ${ }^{28}$ All non-hydrogen atoms were refined with anisotropic displacement parameters. Hydrogen atoms were placed in position of optimized geometry and their isotropic displacement parameters were tied to those of their corresponding carrier atoms by a factor of 1.2 or 1.5. SIMU and ISOR restraints were applied in the refinement of the disorder. The crystallographic data, data collection and structure refinement details are summarized in Table 1 (ESI $\dagger$ ).

At temperatures of $120 \mathrm{~K}$ and $295 \mathrm{~K}$ trans -6 was situated on a general position of space group $P \overline{1}$. While at $120 \mathrm{~K}$ the molecule was well ordered, disorder was observed at higher temperatures. At $295 \mathrm{~K}$ the two pyridyl ligands were subjected to orientational

Table 1 Crystallographic data, data collection and structure refinement details for trans- 6 and cis- 6

\begin{tabular}{|c|c|c|c|c|}
\hline Temperature, $\mathrm{K}$ & 120 & 295 & 305 & 100 \\
\hline Chemical formula & $\mathrm{C}_{54} \mathrm{H}_{62} \mathrm{CoN}_{2} \mathrm{O}_{4}$ & $\mathrm{C}_{54} \mathrm{H}_{62} \mathrm{CoN}_{2} \mathrm{O}_{4}$ & $\mathrm{C}_{54} \mathrm{H}_{62} \mathrm{CoN}_{2} \mathrm{O}_{4}$ & $\mathrm{C}_{54} \mathrm{H}_{62} \mathrm{CoN}_{2} \mathrm{O}_{4} \cdot 4\left(\mathrm{C}_{7} \mathrm{H}_{8}\right)$ \\
\hline Cryst size, mm & $0.30 \times 0.26 \times 0.16$ & $0.30 \times 0.26 \times 0.16$ & $0.30 \times 0.26 \times 0.16$ & $0.50 \times 0.34 \times 0.24$ \\
\hline Cryst sys & Triclinic & Triclinic & Triclinic & Monoclinic \\
\hline Space group & $P \overline{1}$ & $P \overline{1}$ & $P \overline{1}$ & $\mathrm{P} 22_{1} / n$ \\
\hline$c, \AA$ & $19.6875(8)$ & $19.834(2)$ & $12.1278(11)$ & $18.9821(7)$ \\
\hline$\alpha, \operatorname{deg}$ & $101.316(2)$ & $102.162(6)$ & $104.002(5)$ & 90 \\
\hline$\beta, \operatorname{deg}$ & $101.9532(17)$ & $101.446(5)$ & $102.270(5)$ & $107.445(2)$ \\
\hline$\gamma, \operatorname{deg}$ & $103.7626(17)$ & $104.036(5)$ & $101.408(5)$ & 90 \\
\hline$V, \AA^{3}$ & $2313.24(16)$ & $2370.3(4)$ & $1187.49(19)$ & $3510.2(2)$ \\
\hline$Z$ & 2 & 2 & 1 & 2 \\
\hline$\lambda, \stackrel{\AA}{\mathrm{A}} / \mu(\mathrm{K} \alpha), \mathrm{mm}^{-1}$ & $0.71073 / 0.418$ & $0.71073 / 0.408$ & $0.71073 / 0.407$ & $0.71073 / 0.295$ \\
\hline$R_{1}[I>2 \sigma(I)]$ & 0.0348 & 0.0422 & 0.0354 & 0.0394 \\
\hline $\mathrm{w} R_{2} /$ goodness of fit & $0.0921 / 1.042$ & $0.1315 / 1.026$ & $0.0917 / 1.033$ & 0.0998 \\
\hline Residual density, e $\AA^{-3}$ & $+0.480 /-0.368$ & $+0.340 /-0.284$ & $+0.338 /-0.279$ & $+0.487 /-0.367$ \\
\hline
\end{tabular}


disorder affecting the whole ligand moieties. Two alternative orientations of the pyridyl ligand featuring inverted orientations of the central $\mathrm{C}=\mathrm{C}$ double bond were refined resulting in site occupancies of $85.4(3)$ and $14.6(3) \%$ of the 50 involved atoms (for a graphical representation of the disorder see ESI $\dagger$ ). Furthermore, one of the four ${ }^{t} \mathrm{Bu}$ groups was disordered. Here, also two different orientations were refined giving site occupancies of $52(1)$ and $48(1) \%$ for the atoms $\mathrm{C} 22-\mathrm{C} 24$ and C22A-C24A, respectively.

The situation changed at temperatures above $295 \mathrm{~K}$. At $305 \mathrm{~K}$ the complex molecule was now located on a crystallographic inversion center and exhibited crystallographically imposed $C_{\mathrm{i}}$ symmetry. As in the $295 \mathrm{~K}$ structure the pyridyl ligands were subjected to disorder with different orientations of the central $\mathrm{C}=\mathrm{C}$ double bond and were refined resulting in site occupancies of $83.6(6)$ and $16.4(6) \%$ of the involved atoms. Furthermore, one of the crystallographically independent ${ }^{t} \mathrm{Bu}$ groups was disordered. Here, again two different orientations were refined giving site occupancies of $69(2)$ and $31(2) \%$ for the atoms C8-C10 and C8A-C10A, respectively. All three crystal structures of trans-6 point to a ls-Co ${ }^{\mathrm{III}}(\mathrm{Cat})(\mathrm{SQ})$ electronic configuration (vide infra). However, owing to $C_{\mathrm{i}}$ symmetry at $305 \mathrm{~K}$ one cannot distinguish between a mixed-valent delocalized ls-Co ${ }^{\mathrm{III}}$ (Cat)(SQ) $\leftrightarrow$ ls-Co $^{\text {III }}(\mathrm{SQ})(\mathrm{Cat})$ electronic structure and a positional disorder in the localized ls-Co ${ }^{\mathrm{III}}$ (Cat)(SQ) form. ${ }^{\mathbf{1 4 , 2 0}}$ The observation of a crystallographic inversion center at higher temperatures may be due to increasing thermal vibration of atoms accompanied by the incipient valence tautomeric transition as confirmed by magnetic measurements.

Molecules of cis-6 at $100 \mathrm{~K}$ are located on a crystallographic inversion center and exhibit $C_{\mathrm{i}}$ symmetry. The compound crystallized with four molecules of toluene per formula unit. One of the two independent toluene molecules was disordered. Two alternative orientations were refined resulting in site occupancies of 61(1) and 39(1)\% for the atoms C201-C207 and C211-C217. SAME and SIMU restraints were applied in the refinement of the disordered toluene.

\section{Results and discussion}

\section{Syntheses and crystal structures}

The neutral complexes trans-6 and cis-6 were synthesized according to a common procedure for VT cobalt dioxolenes. ${ }^{1}$ Slow precipitation from toluene solutions afforded crystals suitable for X-ray structure determination. ${ }^{29}$ At $120 \mathrm{~K}$ trans-6 reveals a distorted octahedral geometry featuring two equatorial bidentate $o$-dioxolene and two axial monodentate trans-4-stypy ligands (Fig. 1). Short Co-O (1.854(1) $\cdots 1.916(1)$ Å) and Co-N (1.938(1) and 1.945(1) $\AA$ ) distances are characteristic for a lowspin (ls) cobalt(III) ion. Intraligand $\mathrm{C}-\mathrm{O}$ and $(\mathrm{O}) \mathrm{C}-\mathrm{C}(\mathrm{O})$ bond lengths, generally diagnostic of the oxidation level of $o$-dioxolenes, ${ }^{30}$ indicate the presence of a catecholate dianion $\left(\mathrm{Cat}^{2-}\right)$ and a semi-quinone monoanion $\pi$-radical $\left(\mathrm{SQ}^{-}\right)$. The SQ state for one of the ligands is further confirmed by quinoid-type distortion with alternating long-short bonds. Thus, the ligand mixed valency is localized in the solid state at low temperatures.

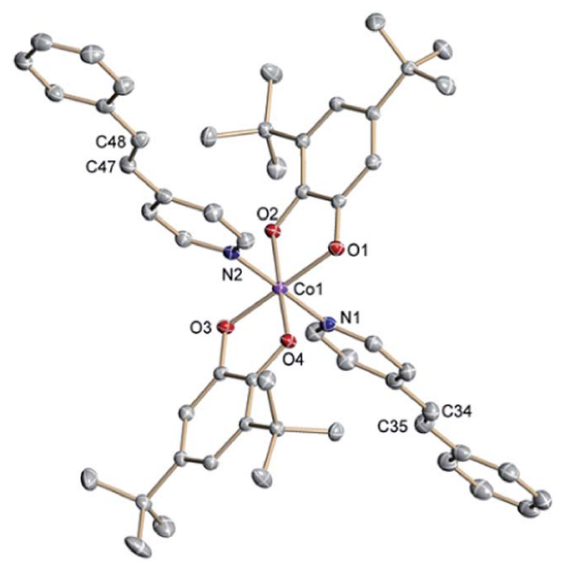

Fig. 1 Molecular structure of trans- 6 determined at $120 \mathrm{~K}$. Thermal ellipsoids are drawn at $50 \%$ probability. Hydrogen atoms are omitted for clarity.

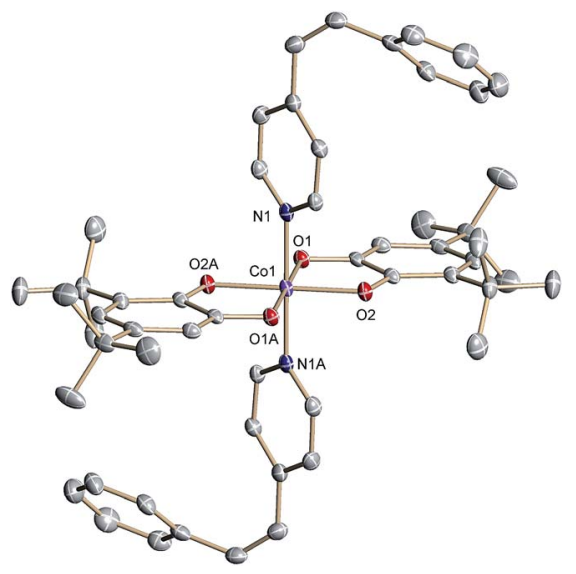

Fig. 2 Molecular structure of cis- 6 determined at $100 \mathrm{~K}$. Thermal ellipsoids are drawn at $50 \%$ probability. Hydrogen atoms are omitted for clarity.

At $T=305 \mathrm{~K}$ all cobalt-ligand bonds remain short, but the quinoid-type distortion is observed in both dioxolenes.

The structurally related cis-6 features two axial cis-4-stypy ligands (Fig. 2). Due to steric factors the pyridyl and phenyl rings of cis-4-stypy cannot be coplanar. Thus, the two rings form a dihedral angle of $50.1^{\circ}$ confining a twisted ethylene bridge. Similar twisted geometry has been observed previously. ${ }^{31,32}$ Short Co-N (1.940(1)) and Co-O (1.885(1) and 1.878(1) $\mathrm{A})$ distances point to a ls-Co ${ }^{\mathrm{III}}$ center at $100 \mathrm{~K}$. Similar to trans-6 at $305 \mathrm{~K}$, intraligand bonds of both 0 -dioxolenes in cis-6 are equally subjected to quinoid type distortion corroborating $\mathrm{Cat}^{2-} / \mathrm{SQ}^{-}$ligand mixed valency.

\section{Magnetic properties in solid state}

The ls-Co ${ }^{\text {III }}$ (Cat)(SQ) ground state for trans-6 is corroborated by magnetic susceptibility measurements on a microcrystalline sample revealing an effective magnetic moment $\mu_{\text {eff }}=1.79 \mu_{\mathrm{B}}$ invariant in the temperature range 8-250 K (see ESI $\dagger$ ). The data could be fitted for a spin doublet $S=1 / 2$ system to afford 
$g=2.064$ and a Weiss constant $\theta=-0.15 \mathrm{~K}$. Hence, based on both, bond length analysis and magnetic measurements, the electronic structure of solid trans-6 below $250 \mathrm{~K}$ is unambiguously assigned as [ls-Co ${ }^{\text {III }}(\mathrm{Cat})(\mathrm{SQ})\left(\right.$ trans-4-stypy $\left._{2}\right]\left(\right.$ trans- $\left.^{\mathbf{L S}}\right)$. At temperatures above $250 \mathrm{~K}$ magnetic moment gradually increased to $4.00 \mu_{\mathrm{B}}$ at $400 \mathrm{~K}$ revealing a thermally induced trans$\mathbf{6}^{\mathbf{L S}} \rightarrow\left[\right.$ hs-Co $^{\mathrm{II}}(\mathrm{SQ})_{2}\left(\right.$ trans-4-stypy $\left._{2}\right]\left(\right.$ trans-6 $^{\mathbf{H S}} ;$ hs $=$ high-spin $)$ transition. The data were fitted with the van't Hoff equation (see ESI $\dagger$ ): with the high-temperature limit of magnetic moment fixed at $5.0 \mu_{\mathrm{B}}$ as a common value for hs-Co ${ }^{\mathrm{II}}(\mathrm{SQ})_{2}$ isomers, ${ }^{13}$ our best fit provides an enthalpy change $\Delta H=41(1) \mathrm{kJ} \mathrm{mol}^{-1}$ and an entropy change $\Delta S=104(3) \mathrm{J} \mathrm{mol}^{-1} \mathrm{~K}^{-1} \cdot{ }^{33}$

Similar to trans-6, magnetic data for solid cis-6 below $250 \mathrm{~K}$ were fitted for an $S=1 / 2$ spin system with $g=2.073$ and $\theta=-0.62 \mathrm{~K}$ (see $\mathrm{ESI} \dagger$ ); and the electronic structure was assigned as [1s-Co ${ }^{\mathrm{III}}(\mathrm{Cat})(\mathrm{SQ})\left(\right.$ cis-4-stypy $\left._{2}\right]\left(\right.$ cis- $\left.^{\mathbf{L S}}\right)$. The thermal transition cis-6 ${ }^{\mathbf{L S}} \rightarrow\left[\mathrm{hs}^{-\mathrm{Co}^{\mathrm{II}}}(\mathrm{SQ})_{2}\left(\right.\right.$ cis-4-stypy $\left._{2}\right]\left(\right.$ cis- $\left.^{\mathbf{H S}}\right)$, indicated by the increase in $\mu_{\text {eff }}$ at higher temperatures, was fitted to yield $\Delta H=52(2) \mathrm{kJ} \mathrm{mol}^{-1}$ and $\Delta S=131(3) \mathrm{J} \mathrm{mol}^{-1} \mathrm{~K}^{-1}$ (see ESI $\dagger$ ). The thermodynamic parameters obtained for both trans-6 and cis-6 in solid state are in agreement with typical thermodynamic parameters for thermally induced VT transitions. ${ }^{34}$ The evolution of $\mu_{\text {eff }}$ with temperature was fully reversible without detectable hysteresis in both cases. Transition temperatures $T_{1 / 2}$ in solid state were estimated at 394 and $397 \mathrm{~K}$ for trans-6 and cis-6, respectively.

\section{Electrochemistry}

Cyclic voltammograms obtained for a $\mathrm{CH}_{2} \mathrm{Cl}_{2}$ solution of trans-6 at RT display one oxidation wave with a half-wave potential $E_{1 / 2}=$ $-0.33 \mathrm{~V}$ and two reduction events at $E_{1 / 2}=-0.67$ and $-1.12 \mathrm{~V}$ versus $\mathrm{Fc}^{+/ 0}$ (see $\mathrm{ESI} \dagger$ ). The ratio between normalized oxidative and reductive peak currents for all three waves are near unity pointing to reversible processes. However, the peak separations $\Delta E$ for reduction events significantly exceed the ideal value of $58 \mathrm{mV}$ expected for a diffusion-controlled reversible one-electron transfer. Very similar cyclic voltammograms measured for cis-6 show one oxidation at $E_{1 / 2}=-0.29 \mathrm{~V}$ and two reductions at $E_{1 / 2}=-0.69$ and $-1.11 \mathrm{~V}$ (see ESI $\dagger$ ). All observed redox events were assigned to the redox-active bis(dioxolene)cobalt core. Yet, a detailed assignment is difficult due to partial dissociation of the complexes in solution (vide infra).

\section{Magnetic properties in solution}

The effective magnetic moment of trans-6 in solution determined by the Evans NMR method ${ }^{26}$ remained nearly constant at $1.7 \mu_{\mathrm{B}}$ below $215 \mathrm{~K}$, which is in agreement with a pure ls-Co ${ }^{\mathrm{III}}$ (Cat)(SQ) state. With rising temperature, $\mu_{\text {eff }}$ gradually increased reaching $4.91(5) \mu_{\mathrm{B}}$ at $353 \mathrm{~K}$ (Fig. 3). These data were fitted using the van't Hoff equation to yield $\Delta H=43(5) \mathrm{kJ} \mathrm{mol}^{-1}, \Delta S=144(16) \mathrm{J}$ $\mathrm{mol}^{-1} \mathrm{~K}^{-1}$ and the high-temperature limit of magnetic moment of $5.1(1) \mu_{\mathrm{B}}$ that is characteristic for a pure hs-Co ${ }^{\mathrm{II}}(\mathrm{SQ})_{2}$ state. The transition temperature $T_{1 / 2}$ was estimated at $299 \mathrm{~K}$.

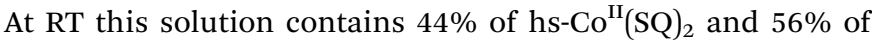
ls-Co ${ }^{\text {III }}$ (Cat)(SQ) species as estimated from RT magnetic moment of $3.59(6) \mu_{\mathrm{B}}$.

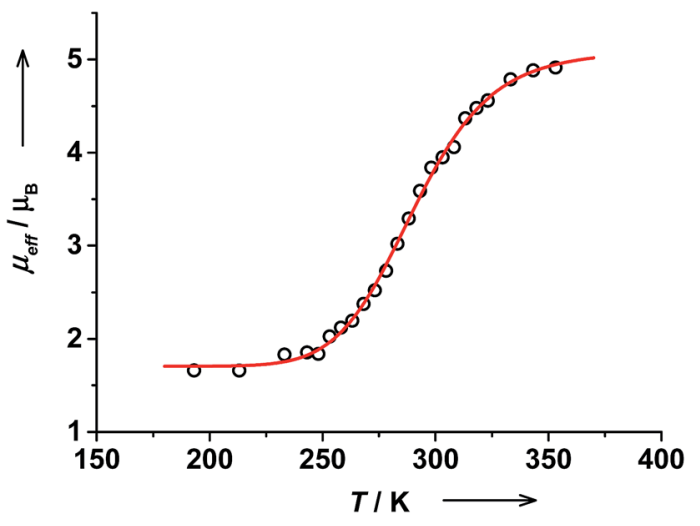

Fig. 3 Temperature dependent effective magnetic moment of trans- 6 dissolved in toluene determined by the Evans method (toluene/[ $\left.\mathrm{D}_{8}\right]$ toluene/TMS $=10: 2: 1)$. Van't Hoff fit parameters: $\Delta H=43(5)$ $\mathrm{kJ} \mathrm{mol}{ }^{-1}, \Delta S=144(16) \mathrm{J} \mathrm{mol}^{-1} \mathrm{~K}^{-1}$; low- and high-temperature magnetic moments: $\mu_{\text {eff }}(\mathrm{LT})=1.69(3) \mu_{\mathrm{B}}$ and $\mu_{\text {eff }}(\mathrm{HT})=5.1(1) \mu_{\mathrm{B}}$. Estimated transition temperature: $T_{1 / 2}=299 \mathrm{~K}$.

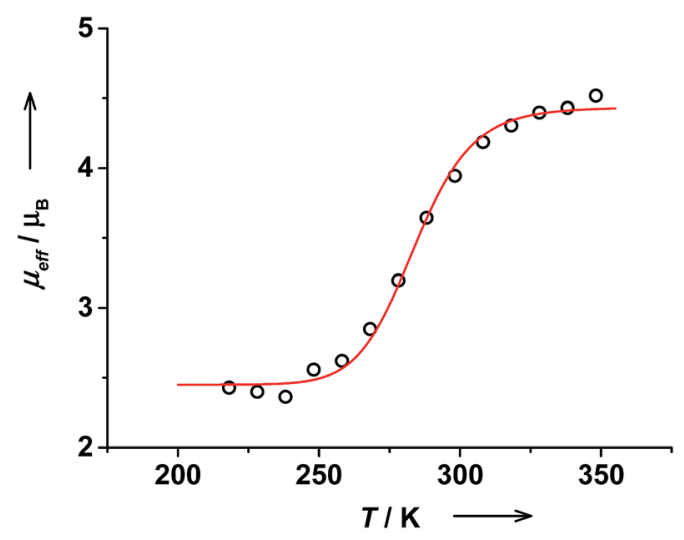

Fig. 4 Temperature dependent effective magnetic moment of cis- 6 dissolved in toluene determined by the Evans method (toluene/[ $\left.D_{8}\right]$ toluene/TMS $=10: 2: 1$ ). Van't Hoff fit parameters: $\Delta H=67(9)$ $\mathrm{kJ} \mathrm{mol}{ }^{-1}, \Delta S=232(33) \mathrm{J} \mathrm{mol}^{-1} \mathrm{~K}^{-1}$; low- and high-temperature magnetic moments: $\mu_{\text {eff }}(\mathrm{LT})=2.45(3) \mu_{\mathrm{B}}$ and $\mu_{\text {eff }}(\mathrm{HT})=4.44(3) \mu_{\mathrm{B}}$. Estimated transition temperature: $T_{1 / 2}=287 \mathrm{~K}$.

Magnetic moment of cis-6 in solution changes gradually from $2.42(6) \mu_{\mathrm{B}}$ at $218 \mathrm{~K}$ to $4.52(6) \mu_{\mathrm{B}}$ at $348 \mathrm{~K}$ (Fig. 4). The data was fitted to give $\Delta H=67(9) \mathrm{kJ} \mathrm{mol}^{-1}$ and $\Delta S=232(33) \mathrm{J} \mathrm{mol}^{-1}$ $\mathrm{K}^{-1}$. The high temperature limit for magnetic moment is 4.44(3) $\mu_{\mathrm{B}}$ that is within the range of typical values for a pure hs$\mathrm{Co}^{\mathrm{II}}(\mathrm{SQ})_{2}$ state. ${ }^{35}$ However, the low temperature limit of $2.45(3)$ $\mu_{\mathrm{B}}$ is higher than expected for a pure ls-Co ${ }^{\mathrm{III}}$ (Cat)(SQ) state. This might be due to the presence of some paramagnetic impurities in solution of cis-6. ${ }^{20}$ The transition temperature $T_{1 / 2}$ was estimated at $287 \mathrm{~K}$. Note, that the $T_{1 / 2}$ value for cis-6 is slightly lower than that for trans-6 in solution (Table 2).

\section{Electronic absorption spectra in solution}

The RT electronic absorption spectrum of trans-6 dissolved in toluene is dominated by a strong band at $307 \mathrm{~nm}\left(\varepsilon=6.1 \times 10^{4}\right.$ $\mathrm{M}^{-1} \mathrm{~cm}^{-1}$ ) arising from $\pi \rightarrow \pi^{*}$ transitions of trans-4-stypy, 
Table 2 Thermodynamic parameters determined for thermally induced transitions in trans -6 and cis- 6 and estimated transition temperature $T_{1 / 2}$

\begin{tabular}{|c|c|c|c|c|c|c|}
\hline Solution (Evans NMR) & $43(5)$ & $144(16)$ & 299 & $67(9)$ & $232(33)$ & 287 \\
\hline Solution (UV-vis) & $56(1)$ & $190(5)$ & 295 & $52(3)$ & 184(11) & 283 \\
\hline Solution (UV-vis, excess 4-stypy) & $39(2)$ & $108(9)$ & 361 & $37(2)$ & $110(7)$ & 336 \\
\hline
\end{tabular}

which overlap with intraligand dioxolene bands (see ESI $\dagger$ )..$^{36,37} \mathrm{~A}$ relatively weak broad band at $750 \mathrm{~nm}\left(\varepsilon=1.8 \times 10^{3} \mathrm{M}^{-1} \mathrm{~cm}^{-1}\right)$ with a shoulder at $\sim 600 \mathrm{~nm}$ are characteristic CT transitions in VT cobalt dioxolenes. ${ }^{2}$ The broad band at $\sim 2650 \mathrm{~nm}$, blighted by solvent overtones in the short-wavelength infrared (SWIR) region, was assigned as an intervalence ligand-to-ligand charge transfer (IVLLCT) transition, which is a spectral fingerprint of mixed-valent ls-Co ${ }^{\text {III }}(\mathrm{Cat})(\mathrm{SQ})$ species (Fig. 7) ${ }^{35}$ The half width $\Delta \nu_{\exp }$ of this band was estimated at $860 \mathrm{~cm}^{-1}$. This value is smaller than the half width calculated using the Hush equation $\Delta \nu_{\text {calcd }}=\left(2310 \times \nu_{\max }\right)^{1 / 2}=2981 \mathrm{~cm}^{-1} \cdot{ }^{38}$ Consequently, trans$\mathbf{6}^{\mathbf{L S}}$ behaves as a class-III fully delocalized ligand mixed-valent system in solution.

At $320 \mathrm{~K}$ the solution of trans-6 appeared green colored and the $600 \mathrm{~nm}$ absorption was nearly buried beneath the broad 750 $\mathrm{nm}$ band. Upon cooling to $259 \mathrm{~K}$, the solution turned bluishgreen, the $750 \mathrm{~nm}$ band decreased in intensity, and the absorption at $600 \mathrm{~nm}$ became more prominent (Fig. 5), which indicates a hs-Co ${ }^{\mathrm{II}}(\mathrm{SQ})_{2} \rightarrow$ ls-Co ${ }^{\mathrm{III}}(\mathrm{Cat})(\mathrm{SQ})$ transition. ${ }^{20}$ Since the available region of our spectrophotometer for variabletemperature measurements is limited to $1020 \mathrm{~nm}$, the spectral evolution in the SWIR region could not be recorded. The temperature dependence of the $750 \mathrm{~nm}$ band was fitted according to the van't Hoff equation to yield $\Delta H=56(1) \mathrm{kJ} \mathrm{mol}^{-1}$ and $\Delta S=190(5) \mathrm{J} \mathrm{mol}^{-1} \mathrm{~K}^{-1}$ (Fig. 6). Consequently, the estimated $T_{1 / 2}$ value for trans-6 is $295 \mathrm{~K}$ that is in very good agreement with the value determined by NMR spectroscopy (299 K).

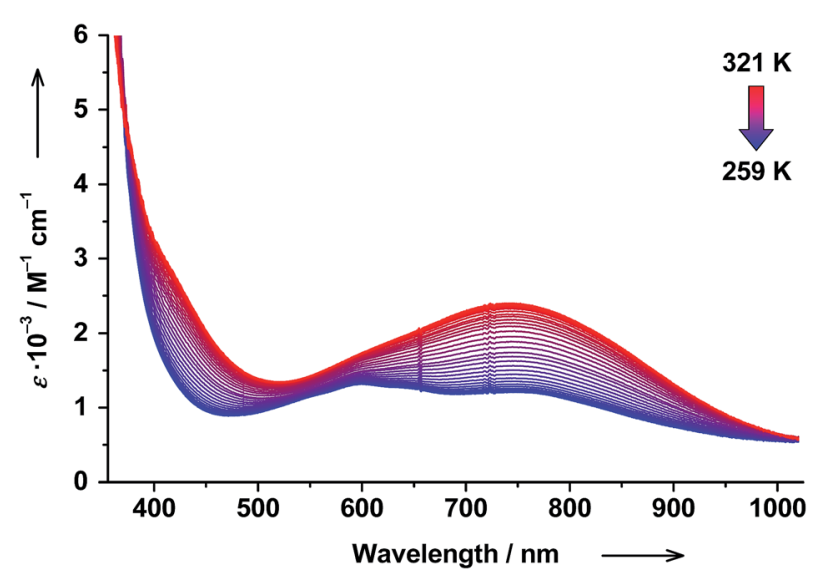

Fig. 5 Temperature-dependent electronic absorption spectra of trans-6 dissolved in toluene.

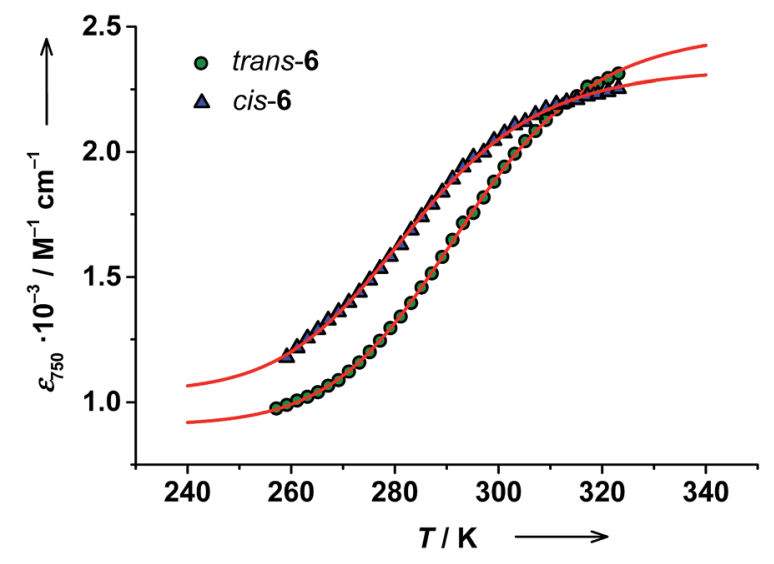

Fig. 6 Temperature dependence of the $750 \mathrm{~nm}$ absorption band of trans -6 and cis -6 dissolved in toluene. van't Hoff fit parameters for trans-6: $\Delta H=56(1) \mathrm{kJ} \mathrm{mol}^{-1}, \Delta S=190$ (5) $\mathrm{J} \mathrm{mol}^{-1} \mathrm{~K}^{-1}$; low- and hightemperature molar extinction coefficients: $\varepsilon(\mathrm{LT})=0.908(3) \times 10^{3} \mathrm{M}^{-1}$ $\mathrm{cm}^{-1}$ and $\varepsilon(\mathrm{HT})=2.490(4) \times 10^{3} \mathrm{M}^{-1} \mathrm{~cm}^{-1}$, estimated transition temperature $T_{1 / 2}=295 \mathrm{~K}$. Fit parameters for cis-6: $\Delta H=52(3) \mathrm{kJ} \mathrm{mol}^{-1}$, $\Delta S=184(11) \mathrm{J} \mathrm{mol}^{-1} \mathrm{~K}^{-1}$; low- and high-temperature molar extinction coefficients: $\varepsilon(\mathrm{LT})=1.041(9) \times 10^{3} \mathrm{M}^{-1} \mathrm{~cm}^{-1}$ and $\varepsilon(\mathrm{HT})=2.337(5) \times 10^{3}$ $\mathrm{M}^{-1} \mathrm{~cm}^{-1}$, estimated transition temperature $T_{1 / 2}=283 \mathrm{~K}$.

Similar to trans-6, a strong band at $306 \mathrm{~nm}\left(\varepsilon=4.2 \times 10^{4}\right.$ $\mathrm{M}^{-1} \mathrm{~cm}^{-1}$ ) caused by cis-4-stypy and dioxolene intraligand transitions was observed for cis-6 solution at RT (see ESI †). As compared to trans-6, the shoulder at $\sim 600 \mathrm{~nm}$ is less developed and the IVLLCT transition at $\sim 2650 \mathrm{~nm}$ is weaker for cis-6 (see ESI $)$. These two features indicate that at RT the $1 s-\mathrm{Co}^{\mathrm{III}}(\mathrm{Cat})(\mathrm{SQ})$ fraction in cis-6 solution is lower than in trans-6 solution. Thus, the VT equilibrium is more shifted toward the hs- $\mathrm{Co}^{\mathrm{II}}(\mathrm{SQ})_{2}$ species in case of cis-6, which is very likely due to weaker coordination of cis-4-stypy (vide infra).

Similar to trans-complex, a color change was observed upon cooling a cis-6 solution. The temperature dependence of absorption at $750 \mathrm{~nm}$ was fitted to give $\Delta H=52(3) \mathrm{kJ} \mathrm{mol}^{-1}$ and $\Delta S=184(11) \mathrm{J} \mathrm{mol}^{-1} \mathrm{~K}^{-1}$. The estimated $T_{1 / 2}$ value of $283 \mathrm{~K}$ is in very good agreement with the value obtained from the Evans method (287 K) (Fig. 6). Again note, that $T_{1 / 2}$ values for cis-6 are slightly lower than those of trans-6 in solution (Table 2).

\section{Titration with 4-stypy ligands}

The thermodynamic parameters obtained for both trans- 6 and cis-6 in solution are larger than those in the solid state and 


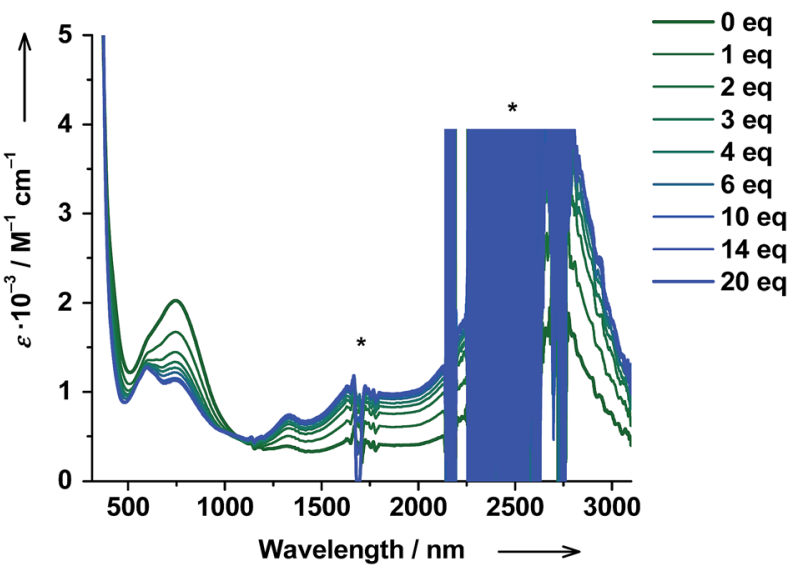

Fig. 7 Changes in absorption spectrum of trans -6 dissolved in toluene upon titration with trans-4-stypy at RT. Signals marked with asterix (*) are due to solvent or change of detector.

clearly exceed typical values for a thermally induced VT transition, which points to partial dissociation. ${ }^{20}$ The presence of a five-coordinate hs-Co ${ }^{\mathrm{II}}(\mathrm{SQ})_{2}$ species trans-5 (Scheme 1) was verified by titrating a solution of trans-6 with trans-4-stypy ligand at RT. Upon addition of the ligand, the green colored solution became bluish-green, the $750 \mathrm{~nm}$ band decreased and absorption at $600 \mathrm{~nm}$ became more developed (Fig. 7). These changes closely resemble those in the variable-temperature experiments (vide supra) and point to a hs-Co ${ }^{\mathrm{II}}(\mathrm{SQ})_{2} \rightarrow$ ls-Co ${ }^{\mathrm{III}}(\mathrm{Cat})(\mathrm{SQ})$ transition. The formation of $1 \mathrm{~s}-\mathrm{Co}^{\mathrm{III}}(\mathrm{Cat})(\mathrm{SQ})$ species upon titration is further corroborated by the growing IVLLCT band at $\sim 2650 \mathrm{~nm}$. An isosbestic point was observed at $1060 \mathrm{~nm}$. Very similar color and spectral changes were observed upon addition of cis-4-stypy ligand to a solution of cis-6 (see ESI $\dagger$ ). Thus, the solution of $c i s-6$ contains some five-coordinate cis-5 species.

Magnetic properties of trans-6 in solution changed on titration as well: the RT magnetic moment decreased gradually from $3.81(6) \mu_{\mathrm{B}}$ (prior to trans-4-stypy addition) to $2.84(7) \mu_{\mathrm{B}}$ after addition of trans-4-stypy (10 eq.). This is in agreement with the suggested hs-Co ${ }^{\mathrm{II}}(\mathrm{SQ})_{2} \rightarrow$ ls-Co ${ }^{\mathrm{III}}(\mathrm{Cat})(\mathrm{SQ})$ switching. Similarly to trans-6, a decrease in $\mu_{\text {eff }}$ from 4.1(1) to 3.1(1) $\mu_{\mathrm{B}}$ was observed upon addition of cis-4-stypy (16 eq.) to a solution of cis-6 (see ESI $\dagger$ ). Thus, the VT states in both trans- and cis-complexes can be switched at RT via addition of corresponding pyridine ligands, as we previously documented in Coordination-Induced Valence Tautomerism (CIVT) effect. ${ }^{20}$

In order to obtain thermodynamic parameters for pure VT transitions between the ls- $\mathrm{Co}^{\mathrm{III}}(\mathrm{Cat})(\mathrm{SQ})$ and $\mathrm{hs}-\mathrm{Co}^{\mathrm{II}}(\mathrm{SQ})_{2}$ redox isomers, we recorded variable-temperature electronic spectra on solutions of trans-6 and cis-6 containing an excess of respective 4-stypy ligand. Thus, the dissociation and formation of five-coordinate species in these solutions must be suppressed. The corresponding van't Hoff fits provided $\Delta H=39(2)$ $\mathrm{kJ} \mathrm{mol}^{-1}$ and $\Delta S=108(9) \mathrm{J} \mathrm{mol}^{-1} \mathrm{~K}^{-1}$ for trans-6 and $\Delta H=$ $37(2) \mathrm{kJ} \mathrm{mol}^{-1}$ and $\Delta S=110(7) \mathrm{J} \mathrm{mol}^{-1} \mathrm{~K}^{-1}$ for cis-6 (see ESI $†$ ). Note, that these values are smaller than those obtained on solutions without excess of 4-stypy ligands and now they are in agreement with typical values reported for VT isomers in solution. ${ }^{35}$

The evolution of the electronic spectrum of trans-6 and the decrease of magnetic moment on titration were both fitted using a non-linear regression approach (see ESI $\dagger$ ). ${ }^{39}$ The intensity of the $750 \mathrm{~nm}$ absorption band as a function of trans-4-stypy concentration (Fig. 8) was fitted to yield an association constant $K_{\mathrm{a}}=4(1) \times 10^{3} \mathrm{~L} \mathrm{~mol}^{-1}$ (eqn (1)). In excellent agreement with this value, a similar fitting for magnetic moment gave $K_{\mathrm{a}}=6(2)$ $\times 10^{3} \mathrm{~L} \mathrm{~mol}^{-1}$ (Fig. 9). Given the values of $K_{\mathrm{a}}$, the toluene solution of the complex must contain $\sim 45 \%$ of the five-coordinate trans-5 and $\sim 55 \%$ of the six-coordinate trans- 6 at given concentrations at RT.

Similarly, the changes of electronic spectrum and magnetic moment of cis-6 upon addition of cis-4-stypy gave $K_{\mathrm{a}}$ values of $1.1(3) \times 10^{3}$ and $0.3(1) \times 10^{3} \mathrm{~L} \mathrm{~mol}^{-1}$, respectively (see ESI $\dagger$ ). Although there is some discrepancy in the values obtained by

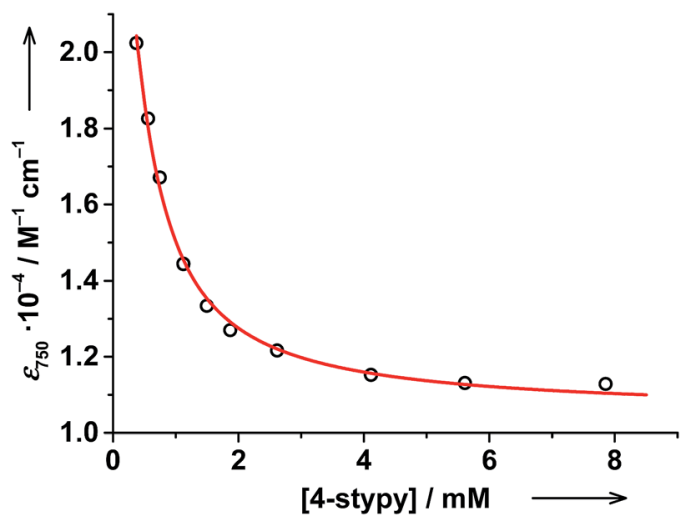

Fig. 8 The evolution of the $750 \mathrm{~nm}$ absorption band of trans- 6 dissolved in toluene upon titration with trans-4-stypy at RT. Non-linear regression fit parameters: $\varepsilon$ (trans $-6 \equiv$ trans $-6^{\mathrm{HS}} \leftrightarrow$ trans $\left.-6^{\mathrm{LS}}\right\}$ ) $=$ $1.05(2) \times 10^{3} \mathrm{M}^{-1} \mathrm{~cm}^{-1}, \varepsilon$ (trans-5) $=2.9(1) \times 10^{3} \mathrm{M}^{-1} \mathrm{~cm}^{-1}, K_{\mathrm{a}}=$ $4(1) \times 10^{3} \mathrm{~L} \mathrm{~mol}^{-1}$.

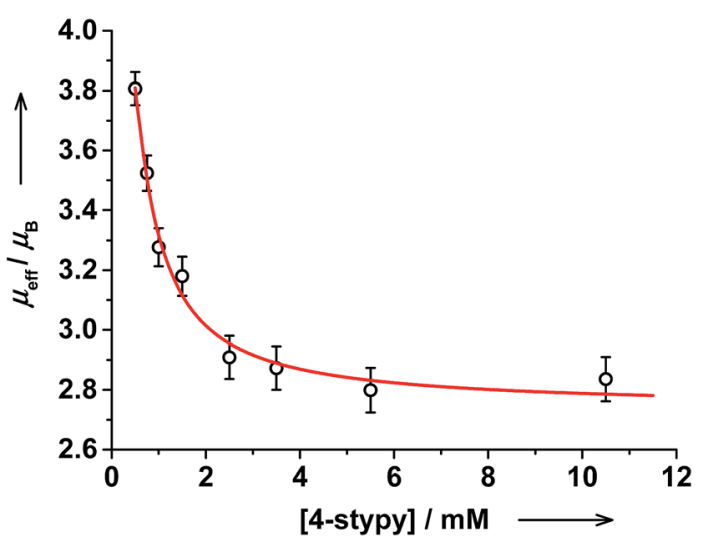

Fig. 9 The evolution of the effective magnetic moment of trans- 6 dissolved in toluene upon titration with trans-4-stypy at RT determined by the Evans method (toluene/[ $\left.\mathrm{D}_{8}\right]$ toluene/TMS $=10: 2: 1$ ). Non-linear regression fit parameters: $\mu_{\text {eff }}\left(\right.$ trans $-6 \equiv\left\{\right.$ trans- $6^{\mathrm{HS}} \leftrightarrow$ trans $\left.\left.-6^{\mathrm{LS}}\right\}\right)=2.51(5) \mu_{\mathrm{B}}, \mu_{\text {eff }}($ trans -5$)=4.7(2) \mu_{\mathrm{B}}$, and $K_{\mathrm{a}}=6(2) \times 10^{3}$ $\mathrm{L} \mathrm{mol}{ }^{-1}$. 
two methods, it is more important that the $K_{\mathrm{a}}$ values for cis-6 are significantly smaller than those for trans-6. Thus, cis-4-stypy is a weaker ligand than trans-4-stypy. This is corroborated by X-ray crystallography, showing that trans-4-stypy ligands in trans-6 are planar thus better $\pi$-acceptors, than non-planar cis-4-stypy ligands in cis-6.

Note, that the RT magnetic moment of dissolved trans-6 decreased to only $2.8 \mu_{\mathrm{B}}$ in the presence of a large excess of trans4-stypy (20 eq.), but not to the low temperature limit of $1.7 \mu_{\mathrm{B}}$. This seeming inconsistency can be readily resolved by considering that the parent trans-6 exists as a mixture of VT isomers trans $^{-6^{\mathbf{L S}}} \leftrightarrow$ trans $^{-\mathbf{6}^{\mathbf{H S}}}$ at RT in solution (eqn (1)). Thus, at low temperatures only trans $-\mathbf{6}^{\mathbf{L S}}$ is present in solution in agreement with the observed magnetic moment of $1.7 \mu_{\mathrm{B}}$. At RT $45 \%$ of trans-6 dissociates to form trans-5 (vide supra). In the presence of a large excess of trans-4-stypy the dissociation is suppressed leaving a mixture of trans $-\mathbf{6}^{\mathbf{L S}}$ and trans $-\mathbf{6}^{\mathbf{H S}}$ at RT. The estimations from magnetic data yield $78 \%$ of trans $-6^{\text {LS }}$ and $22 \%$ of trans $-6^{\mathrm{HS}}$ present in this solution at RT. The same applies to cis6: in the presence of a large excess of cis-4-stypy the equilibrium in solution at RT is virtually shifted to six-coordinate species cis$6^{\mathbf{H S}}$ and cis- $^{\mathbf{L S}}$ (eqn (1)).

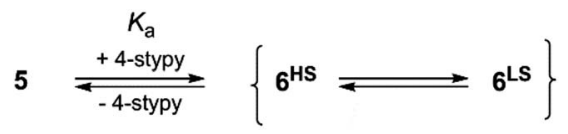

\section{Photochemistry}

Solutions of trans-6 and cis-6 differ in transition temperatures $T_{1 / 2}$ and association constants $K_{\mathrm{a}}$. Consequently, the amount of ls-Co ${ }^{\mathrm{III}}(\mathrm{Cat})(\mathrm{SQ})$ and hs-Co ${ }^{\mathrm{II}}(\mathrm{SQ})_{2}$ species in the two solutions is different. Thus, trans $\leftrightarrow$ cis photoisomerization of 4-stypy ligands offers the opportunity to induce a shift in VT equilibrium and to switch magnetic properties at RT.

When trans-6 solution was irradiated at $\lambda=320 \mathrm{~nm}$, the absorption band at $307 \mathrm{~nm}$ decreased in intensity confirming trans

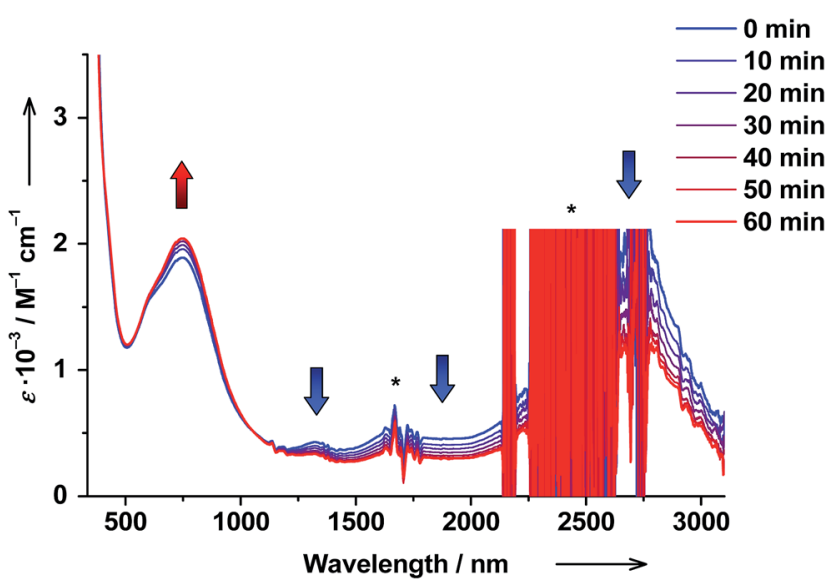

Fig. 10 Changes in absorption spectrum of trans- 6 dissolved in toluene upon UV irradiation at RT $\left(c=3.7 \times 10^{-4} \mathrm{M}, \lambda=320 \pm 8 \mathrm{~nm}\right.$, $1000 \mathrm{~W}$ Xe lamp). Signals marked with asterix $(*)$ are due to solvent or change of detector.

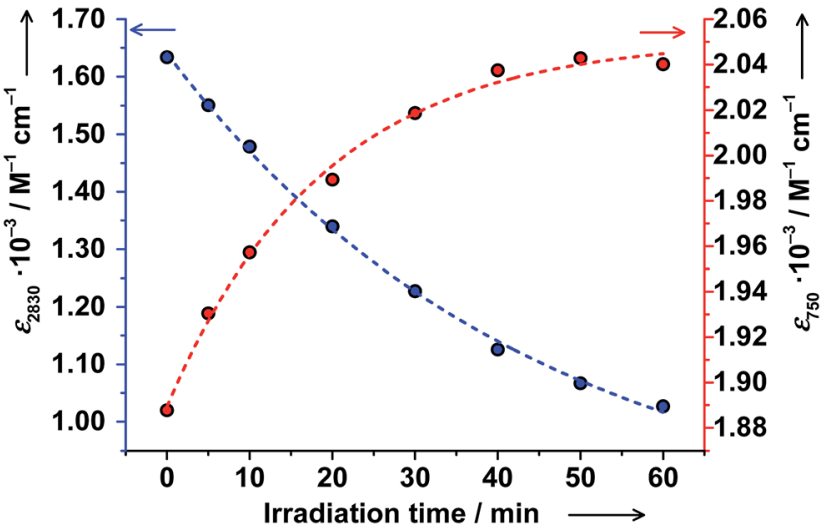

Fig. 11 Changes in absorption at 750 and $2830 \mathrm{~nm}$ of trans- 6 dissolved in toluene upon UV irradiation at RT $\left(c=3.7 \times 10^{-4} \mathrm{M}, \lambda=320\right.$ $\pm 8 \mathrm{~nm}, 1000 \mathrm{~W}$ Xe lamp). The dashed lines serve as guides to the eye.

$\rightarrow$ cis isomerization of 4-stypy (see ESI†). Upon irradiation, the IVLLCT band at $2650 \mathrm{~nm}$ decreased and the CT band at $750 \mathrm{~nm}$ increased revealing an isosbestic point at $1060 \mathrm{~nm}$ (Fig. 10). The photostationary state (PSS) was nearly reached within $60 \mathrm{~min}$ (Fig. 11). It is worth mentioning that very similar spectral changes

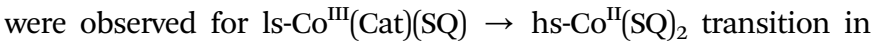
variable-temperature and CIVT experiments (vide supra). Thus, the trans $\rightarrow$ cis photoisomerization of 4-stypy did induce a VT transition in solution at RT.

These results are strongly supported by NMR spectroscopy. Upon irradiation, the magnetic moment increased gradually from 3.53(6) to $4.00(6) \mu_{\mathrm{B}}$ and the PSS was reached within 45 min (Fig. 12). Upon further irradiation, no changes in NMR and electronic spectra were detected verifying stability of the PSS. The amount of ls-Co ${ }^{\mathrm{III}}$ (Cat)(SQ) species decreased from $60 \%$ before irradiation to $43 \%$ after irradiation. Thus, the

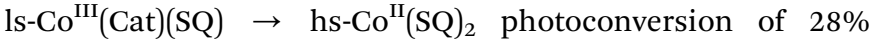
$((60-43) / 60 \times 100)$ was achieved at RT. Importantly, the electronic spectrum and magnetic moment remained unchanged upon storing the irradiated solution at RT for at least 20 hours! Thus, the photogenerated VT state reveals extraordinary

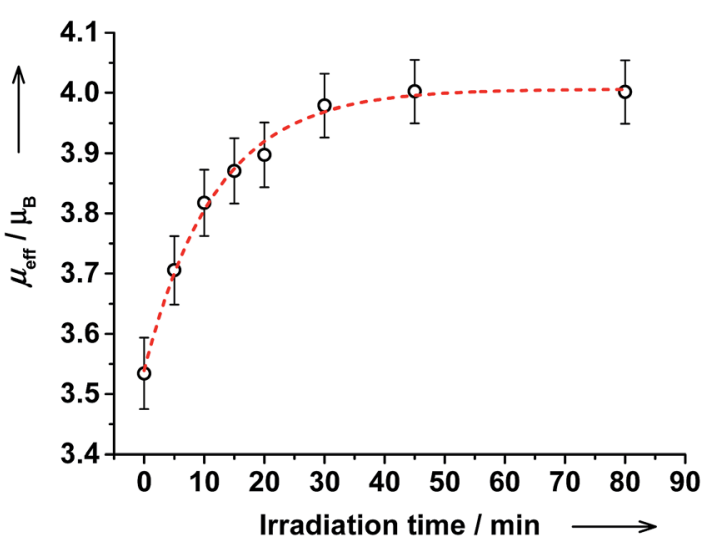

Fig. 12 The evolution of magnetic moment of trans- 6 dissolved in toluene upon UV irradiation at RT determined by the Evans method

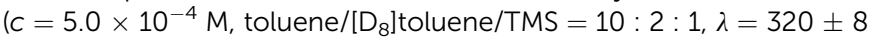
$\mathrm{nm}, 1000 \mathrm{~W}$ Xe lamp). The dashed line serves as a guide to the eye. 


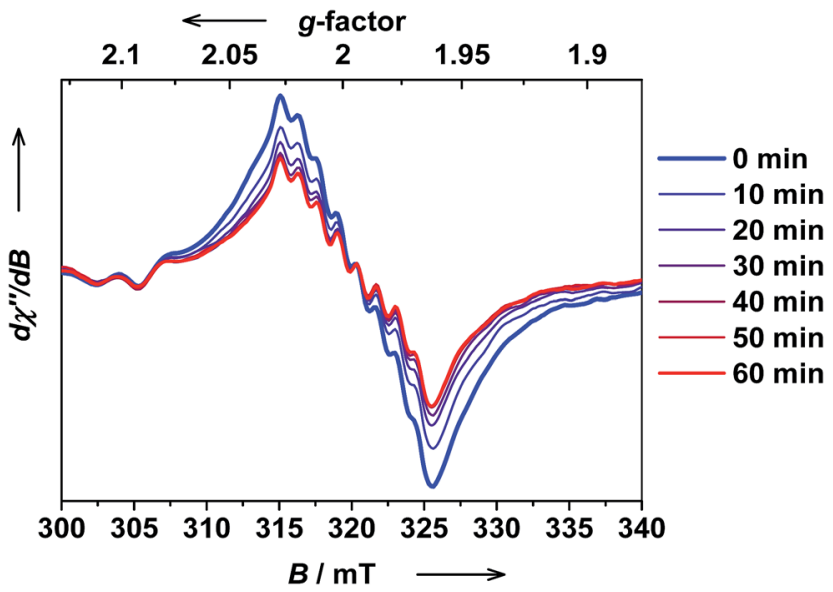

Fig. 13 The evolution of the X-band EPR spectrum of trans- 6 dissolved in benzene upon UV irradiation at RT $\left(c=1.0 \times 10^{-4} \mathrm{M}, \lambda=323\right.$ $\pm 5 \mathrm{~nm}, 150 \mathrm{~W}$ Xe lamp, frequency: $8.9410 \mathrm{GHz}$, modulation: $0.7 \mathrm{mT}$, power: $20 \mathrm{~mW}$ ). Note, that the signal is due to Is-Co $^{\prime \prime \prime}(\mathrm{Cat})(\mathrm{SQ})$, whereas hs-Co" $(\mathrm{SQ})_{2}$ species are not detected. Relatively noisy signal is due to low concentration of trans- 6 , required to speed up bulk photolysis, and consequently very small amount of EPR active Is-Co"I (Cat)(SQ) species present in solution. The spectra of a more concentrated solution and at low temperatures with increased Is-Co"l(Cat)(SQ) content are given in ESI. $\dagger$

thermal stability at RT, as compared to common nanoseconds. $^{8}$ This is to expect, since cis-4-stypy shows exceptional high thermal stability. ${ }^{21}$

The $\mathrm{ls}^{-\mathrm{Co}^{\mathrm{III}}}(\mathrm{Cat})(\mathrm{SQ}) \rightarrow$ hs-Co ${ }^{\mathrm{II}}(\mathrm{SQ})_{2}$ photoswitching in trans-6 solution was further confirmed by EPR spectroscopy. The hs-Co ${ }^{\mathrm{II}}(\mathrm{SQ})_{2}$ isomers are usually EPR silent, whereas the ls-Co ${ }^{\text {III }}$ (Cat)(SQ) state can be readily detected both at low and RT. Thus, a solution of trans-6 at RT shows a typical isotropic spectrum with $g_{\text {iso }}=1.9980$ and a ${ }^{59} \mathrm{Co}$ super-hyperfine coupling constant $A_{\text {iso }}=10.7 \times 10^{-4} \mathrm{~cm}^{-1}$, which is synonymous with a ligand-based radical ${ }^{1 s-C o}{ }^{\mathrm{III}}(\mathrm{Cat})(\mathrm{SQ}){ }^{40}$ Upon in situ irradiation at $\lambda=323 \mathrm{~nm}$ at RT, the signal of ls-Co ${ }^{\text {III }}(\mathrm{Cat})(\mathrm{SQ})$ species gradually decreased, whereas no new signals appeared (Fig. 13). The PSS was reached within $60 \mathrm{~min}$.

We examined the possibility to perform trans $\rightarrow$ cis photoisomerization by low-energy excitation in visible as well. ${ }^{\mathbf{4 1}}$ Whereas irradiation at $\lambda=420$ and $750 \mathrm{~nm}$ did not induce desired photoreaction, irradiation at $\lambda=600 \mathrm{~nm}$ did induce trans $\rightarrow$ cis isomerization. Unfortunately, the latter photoreaction was accompanied by some unidentified side reactions. Thus, the irradiation at $\lambda=320 \mathrm{~nm}$ is the most efficient and clear way to perform trans $\rightarrow$ cis isomerization in trans-6 solution.

The reverse hs-Co ${ }^{\mathrm{II}}(\mathrm{SQ})_{2} \rightarrow \mathrm{ls}^{-\mathrm{Co}^{\mathrm{III}}}(\mathrm{Cat})(\mathrm{SQ})$ photoswitching could be accomplished as well starting from cis-6 complex and performing cis $\rightarrow$ trans ligand-based photoisomerization. When cis-6 solution was irradiated at $\lambda=272 \mathrm{~nm}$, the cis $\rightarrow$ trans photoisomerization of 4-stypy could be unambiguously confirmed by increasing $306 \mathrm{~nm}$ band in electronic spectrum (see ESI $\dagger$ ). Simultaneously, the $750 \mathrm{~nm}$ CT band decreased in intensity, a shoulder at $600 \mathrm{~nm}$ developed, and the LLIVCT band at $\sim 2650 \mathrm{~nm}$ increased before the PSS was reached within $30 \mathrm{~min}$

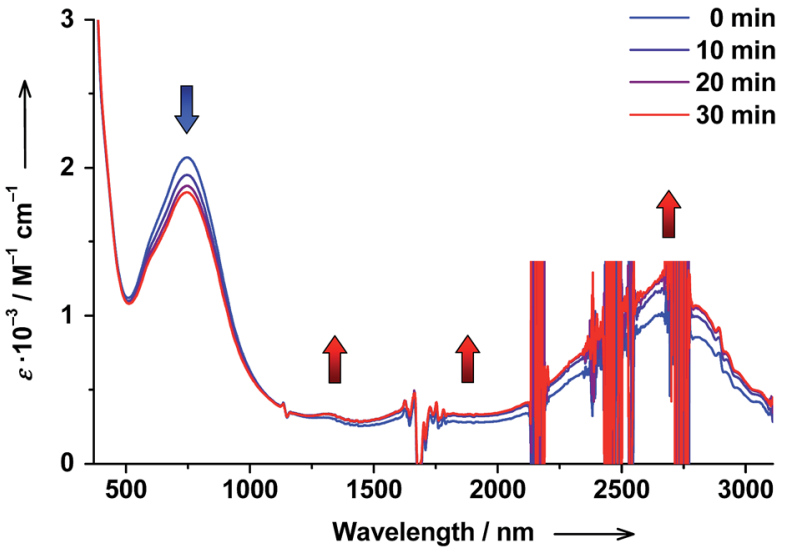

Fig. 14 Changes in absorption spectrum of cis- 6 dissolved in benzene upon UV irradiation at RT $\left(c=5.0 \times 10^{-4} \mathrm{M}, \lambda=272 \pm 8 \mathrm{~nm}, 1000 \mathrm{~W}\right.$ Xe lamp). Signals marked with asterix $(*)$ are due to solvent or change of detector.

(Fig. 14). The observed spectral changes show exactly opposite trends compared to the trans $\rightarrow$ cis photoisomerization experiment. Thus, a cis $\rightarrow$ trans photoisomerization of 4-stypy induces

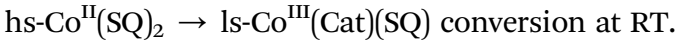

The reverse photoswitching of VT states in cis-6 solution was further corroborated by the decrease of magnetic moment from $3.9(1)$ to $3.7(1) \mu_{\mathrm{B}}$ upon irradiation at $\lambda=272 \mathrm{~nm}$ (Fig. 15). After irradiation the electronic spectrum and magnetic moment remained virtually unchanged during at least 3 hours demonstrating high stability of photogenerated species.

Two mechanisms for the observed photoswitching of VT states should be considered. Upon irradiation at $\lambda=320 \mathrm{~nm}$, trans-4-stypy is converted to cis-4-stypy (coordinated and noncoordinated). The non-planar geometry of cis-4-stypy renders it a weaker $\pi$-acceptor compared to the trans-form. Thus, the ligand field is reduced upon trans $\rightarrow$ cis isomerization, which should stabilize the hs-Co ${ }^{\mathrm{II}}(\mathrm{SQ})_{2}$ state in six-coordinate species 6. At the same time, cis-4-stypy is a weaker coordinating ligand than the trans-isomer, ${ }^{42}$ as was confirmed by differing associate

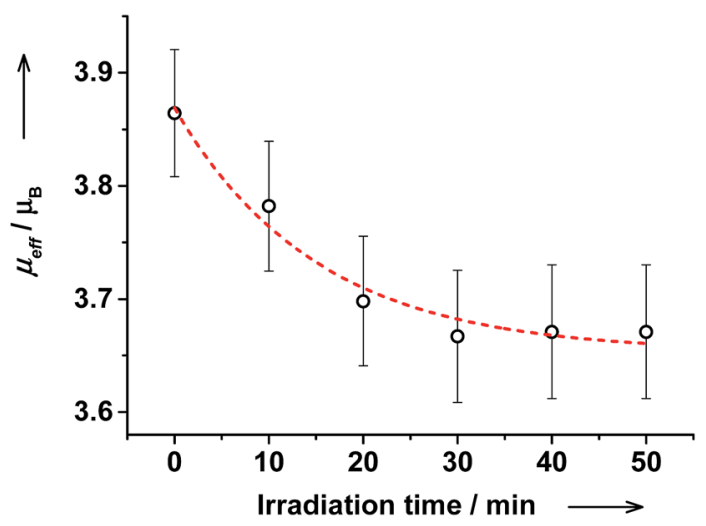

Fig. 15 The evolution of magnetic moment of cis- 6 dissolved in toluene upon UV irradiation at RT determined by the Evans method ( $c=5.0 \times 10^{-4} \mathrm{M}$, toluene/[D $\left.\mathrm{D}_{8}\right]$ toluene/TMS $=10: 2: 1, \lambda=272 \pm 8$ $\mathrm{nm}, 1000 \mathrm{~W}$ Xe lamp). The dashed line serves as a guide to the eye. 
constants (vide supra). Thus, the equilibrium between fivecoordinate 5 and six-coordinate $\mathbf{6}$ species is expected to shift upon trans $\rightarrow$ cis isomerization. In this case some $\left\{\mathbf{6}^{\mathbf{L S}} \leftrightarrow \mathbf{6}^{\mathbf{H S}}\right\}$ species is converted to 5 increasing the hs-Co ${ }^{\mathrm{II}}(\mathrm{SQ})_{2}$ content (eqn (1)).

Similar considerations apply to reverse reaction, when cis-4stypy is converted to trans-4-stypy by irradiating at $\lambda=272 \mathrm{~nm}$. The observed hs-Co ${ }^{\mathrm{II}}(\mathrm{SQ})_{2} \rightarrow$ ls-Co $^{\mathrm{III}}(\mathrm{Cat})(\mathrm{SQ})$ photoconversion may be due to increased ligand field splitting accompanying the cis $\rightarrow$ trans isomerization. Alternatively, the equilibrium between 5 and $\left\{\mathbf{6}^{\mathbf{L S}} \leftrightarrow \mathbf{6}^{\mathbf{H S}}\right\}$ may be shifted toward the sixcoordinate species (eqn (1)) due to stronger coordinating trans4-stypy, thus leading to increased ls-Co ${ }^{\mathrm{III}}$ (Cat)(SQ) content.

To gain a better mechanistic understanding, we performed an irradiation experiment on a trans-6 solution containing a large excess of trans-4-stypy (50 eq.), in which the dissociation is virtually suppressed. Upon extended exposure to UV light the absorption spectrum did not show any detectable changes in visible and SWIR regions characteristic for VT conversion. Therefore, we concluded, that the successful photoswitching of VT states in pristine solutions of trans-6 and cis-6 is unlikely due to variation of the ligand field strength, but to great extent due to the light-induced shift in equilibrium between five- and sixcoordinate species.

It is important to note that the photoswitching of electronic states in trans-6 and cis-6 solutions is of a pure molecular origin. However, the reported irradiation times (typically 30-60 min) correspond the switching of huge number of molecules (bulk photolysis), collectively detected by spectroscopic methods. Since we know how many molecules are switched from ls$\mathrm{Co}^{\mathrm{III}}$ (Cat)(SQ) to hs-Co ${ }^{\mathrm{II}}(\mathrm{SQ})_{2}$ state upon UV irradiation (appr. $\left.10^{17}\right)$, the effective photoswitching rate under our conditions can be estimated as $10^{17}$ molecules $\div 3600 \mathrm{~s}=3 \times 10^{13}$ molecules per s.

In unison with early works by Boillot ${ }^{15}$ and recent works of Herges and Tuczek $^{\mathbf{4 2 , 4 3}}$ on bistable spin-crossover metal complexes, we coin the observed effect Ligand-Driven LightInduced Valence Tautomerism (LD-LIVT).

\section{Conclusions}

In spite of great efforts on the development of molecular photoswitches on the base of valence tautomeric metal complexes during the last decade, the switching with light has been restricted to very low temperatures (usually below $20 \mathrm{~K}$ ). Here, for the first time we have demonstrated light-induced switching in valence tautomeric cobalt complexes at room temperature. The driving force for the photoswitching is bidirectional trans $\leftrightarrow$ cis photoisomerization of 4-styrylpyridine ligands deliberately integrated into bistable magnetic molecules. The photoswitching results in modulation of magnetic properties in solution at room temperature. The novel effect has been coined Ligand-Driven Light-Induced Valence Tautomerism (LD-LIVT) and proceeds at molecular level with very high effective photoswitching rates. Extensive spectroscopic studies reveal photoconversion of $28 \%$ and extraordinary thermal stability of photoinduced states at RT for hours, as compared to common nanoseconds. Consequently, this work may open new horizons in applications of magnetic switches based on valence tautomeric metal complexes in molecular devices functioning at room temperature.

\section{Acknowledgements}

We thank the Fonds der Chemischen Industrie (Liebig Fellowship for MMK) and Deutsche Forschungsgemeinschaft (research grant KH 279/2) for financial support. Prof. Karsten Meyer (Friedrich-Alexander-University of Erlangen-Nuremberg) is acknowledged for general support. We thank Dr Andreas Scheurer and Dr Achim Zahl for assistance with NMR spectroscopy. Fabian Waidhas and Felix Ruf are acknowledged for preliminary photoexperiments with cis-6.

\section{Notes and references}

1 R. M. Buchanan and C. G. Pierpont, J. Am. Chem. Soc., 1980, 102, 4951-4957.

2 D. N. Hendrickson and C. G. Pierpont, Top. Curr. Chem., 2004, 234, 63-95.

3 J. Sedo, J. Saiz-Poseu, F. Busque and D. Ruiz-Molina, $A d v$. Mater., 2013, 25, 653-701.

4 V. I. Minkin, Russ. Chem. Bull., 2008, 57, 687-717.

5 O. Sato, J. Tao and Y.-Z. Zhang, Angew. Chem., Int. Ed., 2007, 46, 2152-2187.

6 A. Dei, D. Gatteschi, C. Sangregorio and L. Sorace, Acc. Chem. Res., 2004, 37, 827-835.

7 T. Tezgerevska, K. G. Alley and C. Boskovic, Coord. Chem. Rev., 2014, 268, 23-40.

8 D. M. Adams, B. L. Li, J. D. Simon and D. N. Hendrickson, Angew. Chem., Int. Ed., 1995, 34, 1481-1483.

9 O. Sato, S. Hayami, Z.-Z. Gu, K. Seki, R. Nakajima and A. Fujishima, Chem. Lett., 2001, 30, 874-875.

10 F. Varret, M. Nogues and A. Goujon, in Magnetism: Molecules to Materials, ed. J. S. Miller and M. Drillon, Wiley-VCH Verlag, New York, 2001, pp. 257-295.

11 O. Sato, A. L. Cui, R. Matsuda, J. Tao and S. Hayami, Acc. Chem. Res., 2007, 40, 361-369.

12 A. Beni, C. Carbonera, A. Dei, J. F. Letard, R. Righini, C. Sangregorio and L. Sorace, J. Braz. Chem. Soc., 2006, 17, 1522-1533.

13 R. D. Schmidt, D. A. Shultz, J. D. Martin and P. D. Boyle, J. Am. Chem. Soc., 2010, 132, 6261-6273.

14 R. D. Schmidt, D. A. Shultz and J. D. Martin, Inorg. Chem., 2010, 49, 3162-3168.

15 M.-L. Boillot, J. Zarembowitch and A. Sour, Top. Curr. Chem., 2004, 234, 261-276.

16 Molecular Switches, ed. B. L. Feringa and W. R. Browne, WILEY-VCH Verlag \& Co. KGaA, Weinheim, Germany, 2011.

17 M. M. Paquette, R. A. Kopelman, E. Beitler and N. L. Frank, Chem. Commun., 2009, 5424-5426.

18 M. Milek, A. Witt, C. Streb, F. W. Heinemann and M. M. Khusniyarov, Dalton Trans., 2013, 42, 5237-5241.

19 M. Milek, F. W. Heinemann and M. M. Khusniyarov, Inorg. Chem., 2013, 52, 11585-11592. 
20 A. Witt, F. W. Heinemann, S. Sproules and M. M. Khusniyarov, Chem.-Eur. J., 2014, 20, 11149-11162.

21 J. L. R. Williams, R. E. Adel, J. M. Carlson, G. A. Reynolds, D. G. Borden and J. A. Ford, J. Org. Chem., 1963, 28, 387-390.

22 R. M. Buchanan, B. Fitzgerald and C. G. Pierpont, Inorg. Chem., 1979, 18, 3439-3444.

23 M.-C. Chiang and W. Hartung, J. Org. Chem., 1945, 10, 21-25.

24 E. Bill and JulX, version 1.5, MPI for Bioinorganic Chemistry, Muelheim/Ruhr, Germany, 2008.

25 F. Neese, Diploma thesis, University of Konstanz, Konstanz, Germany, 1993.

26 D. F. Evans, J. Chem. Soc., 1959, 2003-2005.

27 SADABS 2008/1, Bruker AXS, Inc., Madison, WI, 2009.

28 G. Sheldrick, Acta Crystallogr., Sect. A: Found. Crystallogr., 2008, 64, 112-122.

29 CCDC 1015850-1015852 and 1058866 contain the supplementary crystallographic data for this paper.

30 C. G. Pierpont, Coord. Chem. Rev., 2001, 216, 99-125.

31 C. Roux, J. Zarembowitch, B. Gallois, T. Granier and R. Claude, Inorg. Chem., 1994, 33, 2273-2279.

32 M. L. Boillot, S. Pillet, A. Tissot, E. Rivière, N. Claiser and C. Lecomte, Inorg. Chem., 2009, 48, 4729-4736.

33 Variation of the high-temperature limit of the effective magnetic moment between 5.0 and $6.0 \mu_{\mathrm{B}}$ does not change the fit parameters significantly (see ESI $\dagger$ ).

34 Y. Mulyana, G. Poneti, B. Moubaraki, K. S. Murray, B. F. Abrahams, L. Sorace and C. Boskovic, Dalton Trans., 2010, 39, 4757-4767.
35 D. M. Adams and D. N. Hendrickson, J. Am. Chem. Soc., 1996, 118, 11515-11528.

36 H. Rau, in Photochromism. Molecules and Systems, ed. H. Dürr and H. Bouas-Laurent, Elsevier, Amsterdam, 2003, pp. 64164.

37 N. A. Pavlova, A. I. Poddel'sky, A. S. Bogomyakov, G. K. Fukin, V. K. Cherkasov and G. A. Abakumov, Inorg. Chem. Commun., 2011, 14, 1661-1664.

38 N. S. Hush, in Progress in Inorganic Chemistry, John Wiley \& Sons, Inc., 1967, pp. 391-444.

39 Note, that the non-linear regression fit used to obtain association constants implies only two species involved into equilibrium, whereas actually three species $\left(5, \mathbf{6}^{\mathbf{L T}}\right.$ and $6^{\mathbf{H T}}$ ) are present in solution. However, the employed model is still valid, if the temperature is kept constant and thus the ratio between $6^{\mathbf{L T}}$ and $\mathbf{6}^{\mathbf{H T}}$ remains constant too. Hence, the model describing the equilibrium between $\mathbf{5}$ and a quasi-species $\left\{\mathbf{6}^{\mathbf{L T}} \leftrightarrow \mathbf{6}^{\mathbf{H T}}\right\}$ is correct.

40 D. M. Adams, L. Noodleman and D. N. Hendrickson, Inorg. Chem., 1997, 36, 3966-3984.

41 A. Tissot, M.-L. Boillot, S. Pillet, E. Codjovi, K. Boukheddaden and L. M. L. Daku, J. Phys. Chem. C, 2010, 114, 21715-21722.

42 S. Thies, H. Sell, C. Schütt, C. Bornholdt, C. Näther, F. Tuczek and R. Herges, J. Am. Chem. Soc., 2011, 133, 16243-16250.

43 S. Venkataramani, U. Jana, M. Dommaschk, F. D. Sonnichsen, F. Tuczek and R. Herges, Science, 2011, 331, 445-448. 